\title{
Impairment of resin cement application on the bond strength of indirect composite restorations
}

Jovito Adiel SKUPIEN(a) José Augusto Sedrez PORTO(a) Eliseu Aldrighi MÜNCHOW(a) Maximiliano Sérgio $\mathrm{CENCI}^{(b)}$ Tatiana PEREIRA-CENCI(c)

(a) Universidade Federal de Pelotas - UFPel, Graduate Program in Dentistry, Pelotas, RS, Brazil.

(b) Universidade Federal de Pelotas - UFPel, Dental School, Department of Restorative Dentistry, Pelotas, RS, Brazil.

(c) Universidade Federal de Pelotas - UFPel, Dental School, Department of Prosthodontics, Pelotas, RS, Brazil.

Declaration of Interests: The authors certify that they have no commercial or associative interest that represents a conflict of interest in connection with the manuscript

Corresponding Author:

Jovito Adiel Skupien

E-mail: skupien.ja@gmail.com

DOI: 10.1590/1807-3107BOR-2015.vol29.0066

Submitted: Sep 12, 2014

Accepted for publication: Feb 06, 2015

Last revision: May 04, 2015

\begin{abstract}
The aims of this study were to evaluate the effect of immediate and delayed resin cement application on the microtensile bond strength of indirect composite resin restorations and, to evaluate adhesive strategies (for regular resin cement or humidity parameters for self-adhesive resin cement). Forty-five enamel/dentin discs (0.5 mm height and $10 \mathrm{~mm}$ of diameter) obtained from bovine teeth were divided into nine groups $(n=5)$. For regular cement, the variation factors were cementation technique at three levels (immediate cementation, 5 or $30 \mathrm{~min}$ after adhesive system application); and type of adhesive system at two levels (three- or two-step). For self-adhesive cement, the dentin moisture was the source of variation at three levels (normal, dry, or wet cementation). The specimens were submitted to microtensile bond strength $(\mu \mathrm{TBS})$ testing using a universal testing machine. Data were analyzed by ANOVA, Tukey's test, and linear regression. Regular cement and three-step etch-and-rinse adhesive system showed the highest values of bond strength (25.21 MPa-30 min of delay). Only for this condition, three-step adhesive showed higher bond strength than the two-step adhesive. Nevertheless, the linear regression showed that irrespective of the strategy, the use of the two-step approach when compared with three-step adhesive system decreased $\mu$ TBS $(p<0.001)$. The failure analysis showed predominant adhesive failures for all tested groups. All groups had comparable values of bond strength to bovine dentin when the same materials were used, even in suboptimal clinical conditions.
\end{abstract}

Keywords: Composite Resins; Dentin-Bonding Agents; Dental Cements.

\section{Introduction}

Indirect restorations have been commonly chosen over direct restorative materials to restore dental tissues, mainly because it is easier to create better anatomical and contour characteristics in addition to the improved physical properties of indirect materials when compared to direct restoratives. ${ }^{1}$ Cementation of indirect restorations with resin cements depends greatly on the type of adhesive strategy used to hybridize the substrate, ${ }^{2}$ where regular cements should be applied only after the application of adhesive systems [three-, two-, or one-step(s)].$^{3,4}$ Self-adhesive cements can also be used, although there is no need of previous application of bonding agents to the substrate. 
Bonding to dentin is a complex procedure that requires satisfactory wet condition of the substrate. ${ }^{5}$ Even with the evolution of adhesive systems and hybridization techniques in "dry dentin", it is clear that water plays an important role in dentin bonding. During restoration build-up, the presence of water can result from contamination, incorrect rinsing and drying procedures, or even from the dentin itself, since water can flow and overcome the hybrid layer, ${ }^{6}$ which may jeopardize the dentin-resin interface, and therefore, affect the longevity of restorations. ${ }^{7,8,9,10}$

In routine clinical practice, time is one of the most important factors from both patient's and clinician's perspective. If an extensive rehabilitation treatment involving several teeth is proposed, all the hybridization processes, which in theory should be individually performed, can be time consuming. As an alternative to overcome this situation, numerous dentists simultaneously perform the adhesive application in all teeth involved in the process. Such procedure with posterior restoration build-up and/or cementation of indirect restorations could promote an inappropriate adhesion, and consequently, influence the durability of the restorations. In addition, the risk of contamination is higher with longer time elapses after bonding procedures, which could jeopardize the adhesive interface, and consequently, negatively influences the longevity of the restoration.

Therefore, the aims of the present study were to evaluate the impairment of immediate or delayed resin cement application on the microtensile bond strength ( $\mu$ TBS) of indirect composite resin, and to evaluate adhesive strategies (for regular resin cement) and humidity conditions of the substrate (for self-adhesive resin cement). The hypotheses evaluated were as follows: (1) the cementation delay would reduce the bond strength of the restorations, irrespective of the adhesive strategy used; and (2) the cementation strategy (type of resin cement) directly influences the bond strength of cemented composite resin restorations.

\section{Methodology}

This was a completely randomized, blinded ( $\mu$ TBS evaluation) in vitro study regarding resin cement, type of adhesive system, time to cementation, and moist condition of substrate as factors during the study. Forty-five single-rooted bovine mandibular incisors were selected. The teeth were analyzed for potential failures that could compromise the results as cracks, fractures, or caries. Next, teeth were washed, cleaned, and stored in $0.5 \%$ thymol solution for a maximum of two months until use.

Discs of dentin and enamel were obtained from bovine incisors using a water-cooled trephine diamond drill. Next, enamel was ground off with 180-grit $\mathrm{SiC}$ paper, and dentin discs were polished using a sequence of 400-, 600-, 1200-, and 2000-grit SiC papers under water irrigation followed by a final polish through a cotton disc with $1.0 \mu \mathrm{m}$ diamond paste. The dentin discs measured 3-4 $\mathrm{mm}$ in height and $5 \mathrm{~mm}$ in diameter.

Discs of composite resin with the same dimensions as the dentin discs were obtained using a polyvinyl siloxane (Express XT, 3M ESPE, St. Paul, USA) mold, obtained with the impression of the respective enamel/dentin specimen. The mold was filled with composite resin (Filtek Z-250, 3M ESPE, St. Paul, USA) and light-polymerized (Olsen, Maringá, Brazil) for $2 \mathrm{~min}$ at $800 \mathrm{~mW} / \mathrm{cm}^{2}$ on each surface. The specimens were removed from the mold, and the discs were again light-polymerized. Next, the surface to be cemented was sandblasted ( $25 \mu \mathrm{m}$ aluminum oxide) at a $10 \mathrm{~mm}$ distance from the disc for $20 \mathrm{~s}$ with a pressure of 2.8 bar. As a final step, the specimens were cleaned ultrasonically in deionized water for $3 \mathrm{~min}$.

The discs of dentin and composite resin were randomly divided into nine groups $(n=5)$, according to the materials and cementation strategies described in Table 1 . The groups were nominated according to the materials used: R-Regular Cement; S-Self-adhesive Cement; 3-Three-step Adhesive System; 2-Two-Step Adhesive System; Im-Immediate Cementation; 5 min- 5 minutes of Delayed Cementation; 30 min-30 minutes of Delayed Cementation; No-Normal Dentin; Dr-Dry Dentin; and Mo-Moist Dentin. In all groups, the surface of the composite resin discs to be cemented was covered with a thin layer of silane (Angelus, Londrina, Brazil) and sandblasted prior to cementation. The cementation was performed on a glass plate with a piece of gauze irrigated with $5 \mathrm{~mL}$ of distilled 
water, to simulate dentin humidity. The discs (teeth and restoration) were positioned with the dentin in contact with the gauze, and a second glass plate was placed on top with a customized weight of $750 \mathrm{~g}$, in order to standardize the cementation pressure. Each cementation was performed individually.

After cementation, the specimens were stored in distilled water at $37^{\circ} \mathrm{C}$ for $24 \mathrm{~h}$ and longitudinally sectioned in two directions perpendicular to the adhesive interface to obtain beam-shaped specimens. The cross-sectional area of the bond interface of each beam was measured with a digital caliper (Mitutoyo Corporation, Tokyo, Japan). After storage, the beams were positioned in a $\mu$ TBS testing device with top-bottom fixation with cyanoacrylate and subjected to a microtensile test in a mechanical testing machine (DL500; EMIC, São José dos Pinhais, Brazil) at a crosshead speed of $0.5 \mathrm{~mm} / \mathrm{min}$ until failure. Bond strength values were calculated in $\mathrm{MPa}$. Fractured beam-shaped specimens were evaluated with a stereomicroscope (Olympus/DeTrey, Konstanz, Germany) at 40× magnification to determine the mode of failure: in adhesive (interface), cohesive (dentin or composite resin), or mixed (adhesive and cohesive). Failures located outside of the gauge region were considered right-censored data points. The data were analyzed using SPSS 19 for Mac (SPSS Inc., Chicago,
USA). ANOVA followed by Tukey post hoc comparison was used to analyze the fracture resistance results at a significance level of $5 \%$. The experimental unit used for the analysis was the beam, and pre-failure were only considered in descriptive statistics. In addition, linear regression analysis investigated the influence of variables on bond strength values.

\section{Results}

Groups cemented with regular cement and three-step etch-and-rinse adhesive system showed higher $\mu$ TBS values than groups with self-adhesive cement, as described in Table 2. The highest bond strength value was obtained with 30 min of delay in the regular cement group, but only for this condition, three-step adhesive showed higher bond strength than two-step one. Furthermore, a moist condition did not influence bond strength for self-adhesive cement. The failures were predominantly adhesive followed by mixed failures. Premature failures were those that occurred during the handling of specimens and mainly occurred in groups where the self-adhesive cement was employed. The total number of specimens is also presented in Table 2.

A linear regression analysis was performed to eliminate groups and assess differences considering the two conditions: time of cementation and adhesive

Table 1. Materials used and groups distribution.

\begin{tabular}{|c|c|c|c|}
\hline Group & Materials & Strategy & Steps* \\
\hline R3-Im & $\begin{array}{l}\text { Regular Resin Cement RelyX ARC (3M ESPE) + Three-Step } \\
\text { etch-and-rinse adhesive system Scotchbond Multi-Purpose (3M ESPE) }\end{array}$ & $\begin{array}{l}\text { Immediate cementation after } \\
\text { hybridization }\end{array}$ & $1,2,3,4,5,6,7,8$ and 9 \\
\hline R3-5 min & RelyX ARC + Scotchbond Multi-Purpose & Cementation 5 min after hybridization & $1,2,3,4,5,6,7,8$ and 9 \\
\hline R3-30 min & RelyX ARC + Scotchbond Multi-Purpose & Cementation 30 min after hybridization & $1,2,3,4,5,6,7,8$ and 9 \\
\hline R2-Im & $\begin{array}{c}\text { RelyX ARC + Two-Step etch-and-rinse adhesive system Adper } \\
\text { Single Bond (3M ESPE) }\end{array}$ & $\begin{array}{l}\text { Immediate cementation after } \\
\text { hybridization }\end{array}$ & $1,2,3,5,6,7,8$ and 9 \\
\hline R2-5 min & RelyX ARC + Adper Single Bond & Cementation 5 min after hybridization & $1,2,3,5,6,7,8$ and 9 \\
\hline $\mathrm{R} 2-30 \mathrm{~min}$ & RelyX ARC + Adper Single Bond & Cementation 30 min after hybridization & $1,2,3,5,6,7,8$ and 9 \\
\hline S-No & Self-adhesive Resin Cement RelyX U100 (3M ESPE) & Cementation in normal dentin ${ }^{@}$ & $2,3,8$ and 9 \\
\hline S-Dr & RelyX U100 & Cementation in dry dentin* & $2,3,8$ and 9 \\
\hline S-Mo & RelyX U100 & Cementation in moisture dentin $\$$ & $2,3,8$ and 9 \\
\hline
\end{tabular}

Step 1: Phosphoric acid application for 15 s; Step 2: Rinsing with air-water spray for 30 s; Step 3: Gently air dry for 10 s; Step 4: Primer application under friction for $5 \mathrm{~s}$; Step 5: Adhesive application; Step 6: Repeat step 3; Step 7: Light-polymerization for 40 s; Step 8: Cement manipulation and cementation of the discs; Step 9: Light-polymerization for $60 \mathrm{~s}$ in four sides of the complex plus $60 \mathrm{~s}$ each surface after remove the weight used to cementation.

@ - Dentin drying with absorbent papers $\left(1 \mathrm{~cm}^{2}\right)$.

\# - Dentin drying with absorbent papers $\left(1 \mathrm{~cm}^{2}\right)$ followed by strong air dry for $60 \mathrm{~s}$.

$\$$ - Dentin drying with absorbent papers $\left(1 \mathrm{~cm}^{2}\right)$ followed by irrigation of $2 \mathrm{ml}$ of distillated water. 
Table 2. Mean values of $\mu$ TBS (SD) for all groups and the frequencies of failures.

\begin{tabular}{|c|c|c|c|c|c|c|c|}
\hline Group & $\mu \mathrm{TBS}$ in $\mathrm{MPa}$ & $\begin{array}{l}\text { Adhesive } \\
\text { Failure }\end{array}$ & $\begin{array}{l}\text { Cohesive in } \\
\text { Resin }\end{array}$ & $\begin{array}{l}\text { Cohesive in } \\
\text { Dentin }\end{array}$ & Mixed & Premature Failure & $\begin{array}{l}\text { Total of Beam-shaped } \\
\text { Specimens }\end{array}$ \\
\hline R3-Im & $20.29( \pm 12.75)^{\mathrm{AB}}$ & 22 & 1 & 2 & 8 & 9 & 42 \\
\hline R3-5 min & $20.44( \pm 9.09)^{\mathrm{AB}}$ & 24 & 0 & 1 & 7 & 6 & 38 \\
\hline R3-30 min & $25.21( \pm 8.68)^{A}$ & 21 & 1 & 1 & 20 & 3 & 46 \\
\hline $\mathrm{R} 2-\mathrm{Im}$ & $17.68( \pm 12.82)^{\mathrm{B}}$ & 24 & 0 & 0 & 10 & 8 & 42 \\
\hline $\mathrm{R} 2-5 \mathrm{~min}$ & $14.62( \pm 8.09)^{\mathrm{BC}}$ & 19 & 0 & 0 & 7 & 13 & 39 \\
\hline $\mathrm{R} 2-30 \mathrm{~min}$ & $13.75( \pm 6.51)^{\mathrm{BC}}$ & 28 & 1 & 0 & 4 & 11 & 44 \\
\hline S-No & $9.69( \pm 5.27)^{\mathrm{CD}}$ & 30 & 0 & 0 & 0 & 13 & 43 \\
\hline S-Dr & $7.82( \pm 6.08)^{\mathrm{CD}}$ & 29 & 0 & 1 & 1 & 9 & 40 \\
\hline S-Mo & $6.07( \pm 3.74)^{\mathrm{D}}$ & 22 & 0 & 0 & 0 & 19 & 41 \\
\hline
\end{tabular}

Different upper case letters represent statistically significant results (Tukey test; $p<0.05$ )

R - Regular Cement; S - Self-adhesive Cement; 3 - Three-step Adhesive System; 2 - Two-Step Adhesive System; Im - Immediate Cementation;

5 min - 5 minutes of Delayed Cementation; 30 min - 30 minutes of Delayed Cementation; No - Normal Dentin; Dr - Dry Dentin; Mo - Moist Dentin.

system/technique. The analysis was performed only in the regular cement groups, because application of adhesive did not take place in the self-adhesive group. Thus, type of adhesive significantly influenced $\mu \mathrm{TBS}$ values ( $p<0.0001)$, whereas there was no effect of delayed cementation on $\mu$ TBS values $(p=0.623)($ Table 3$)$.

\section{Discussion}

In our study, the effect of delayed cementation was investigated using only regular cement after the application of two different etch-and-rinse adhesive systems (three-step or two-step), because there is no need for adhesive with self-adhesive cement, and the hybridization of dentin was not a real problem for the self-adhesive cement in our study. However, the comparison between these two cements was considered for the following reasons: the regular cement could result in higher bond strengths even with delayed cementation; and the self-adhesive cement, although easier to handle, could result in lower bond strength values.

As the bond strength is ultimately the main outcome responsible for the survival of the tooth-restoration complex, the cementation delay could result in clinical problems. The real problem regarding cementation delay is the possible contamination of the hybridized dentin/adhesive layer with humidity or other substances present in the oral environment. However, even though our study did not evaluate contamination, it could be verified that the type of
Table 3. Linear regression model, with the two independent variables (R-square $=0.106)$.

\begin{tabular}{lcccc}
\hline Variable & Effect & $\begin{array}{c}95 \% \text { Confidence Interval } \\
\text { Lower } \quad \text { Upper }\end{array}$ & Significance \\
\hline (Constant) & 28.73 & & & \\
Adhesive & -6.85 & {$[-9.69 \ldots \ldots \ldots \ldots .4 .01]$} & $<0.001$ \\
Time & 0.418 & {$[-1.26 \ldots \ldots \ldots \ldots . .2 .09]$} & 0.623 \\
\hline
\end{tabular}

adhesive system significantly influenced the bond strength values of the cemented restorations, with the application of a three-step adhesive producing slightly higher bond strength than the two-step adhesive. This may be explained by the third step of the former system, which creates a hydrophobic layer, and consequently, the prevention of water trespassing through the hybrid layer. ${ }^{3}$

According to our results, the cementation delay of 5 or 30 minutes after hybridization resulted in similar bond strength when compared with the groups where cementation occurred immediately, irrespective of the type of adhesive used. Hence, the first hypothesis that cementation delay would reduce the bond strength of the restorations was rejected. Etch-and-rinse adhesive systems have been well recognized as good adhesion bonding agents, even when applied to dentin. ${ }^{3}$ In addition, when the adhesive substance is applied and light-activated, the most superficial zone of the adhesive layer is not polymerized due to oxygen contact inhibition; ${ }^{11}$ thus, the adhesive remains reactive and can chemically 
interact with the next material applied, i.e., resin cement or composite resin, even if applied with a delay. Consequently, the regular resin cement applied immediately or with a delay of 5 or 30 minutes was equally able to bond with the hybridized dentin, explaining the results obtained in the present study.

Conversely to the results of the delayed cementation groups, cementation strategy was confirmed as being a factor that can affect bond strength, corroborating other studies. ${ }^{12,13}$ The group, where restorations were cemented with regular cement, demonstrated better results when compared to self-adhesive resin cement groups, especially when the three-step etch-and-rinse adhesive system was applied, as previously shown.14,15,16 Despite the low initial $\mathrm{pH}$ of the self-adhesive resin cement used, it presents low demineralization effect, and consequently, inadequate formation of the hybrid layer, ${ }^{17,18}$ thus explaining the low bond strength values. On the basis of these results, the second hypothesis investigated, according to which the cementation strategy (type of resin cement) directly influences the bond strength of cemented composite resin restorations, can be accepted.

A recent systematic review and meta-analysis stated that the use of self-adhesive resin cements enhanced bond strength of glass-fiber posts luted into root canals when compared to the use of regular cements. ${ }^{19}$ These results were different from our findings; however, it is important to emphasize that fiber post retention depends of several factors other than only bonding interface. Thus, it is possible to affirm that depending on the application purpose of resin cements, different results may occur. In our study, cementation with the self-adhesive cement was performed varying the moisture of the dentin substrate, as water may play an important role in the bonding ability of self-adhesive materials. However, there were no differences in the bond strength performance of restorations cemented in over-dried or over-wet dentin when compared with those cemented in adequately moist dentin. In addition, as this cement was used in an "inaccurate" technique and presented comparable values, it can achieve reliable bonding even under unfavorable circumstances. Moosavi et $a l .{ }^{20}$ also showed that different moisture conditions did not affect $\mu$ TBS of self-adhesive resin cement.
Likewise, other variables such as handling, aging, ${ }^{15}$ and pulpal pressure ${ }^{16}$ did not affect the resistance, demonstrating that even if presenting lower bond strength values, cementation with this material can offer advantages that could also affect the outcome, as less sensitive to variations.

The measurement of cement thickness was not performed because the same cementation pressure procedures were used. However, it does not ensure that all specimens had the same thickness, mainly because of different flow characteristics of different cements, which can influence stress concentration during $\mu$ TBS testing, where stress concentration will increase with greater cement thickness. The curing protocol was the same for all groups, which benefited the regular cement groups, because the polymerization step of this group is most challenging in difficult cases, such as when access to light is limited. The same protocol was used for adhesive procedures prior to the use of regular resin cement, which can also be difficult to perform in some situations, and for both cases described above, a resin cement, such as RelyX U100, is usually recommended.

To reinforce the influence of adhesive, a linear regression was performed to evaluate time and adhesive system in the same analysis. Despite the low R square, it was demonstrated that the three-step adhesive system could increase the average $\mu \mathrm{TBS}$ by $6.85 \mathrm{MPa}$ compared with the two-step adhesive system. Moreover, the values were similar to other studies that used $\mu$ TBS to evaluate adhesive systems, whereas the best performance was achieved by three-step adhesive system. ${ }^{21,22}$ Consequently, $\mu$ TBS can be considered as a reliable method for measuring bond strength under the test conditions in this study. Besides creating several beam-shaped specimens through a single tooth, additional adhesive failures were detected, which reflects a true measurement of resistance. ${ }^{23,24}$

The failures observed in the present study were prominently in the adhesive interface for all groups. However, only three cohesive failures in resin and five in dentin was distributed in five different groups, demonstrating the consistency of the methodology employed. RelyX ARC used with Scotchbond Multi-Purpose presented more 
mixed failures, which appears to be related with the highest $\mu$ TBS value observed. The number of premature failures, i.e., before microtensile testing, was also proportional to the $\mu$ TBS values, with RelyX U100 used in dry dentin presenting 19 pre-testing failures. Moreover, the modulus of elasticity of self-adhesive resin cement is slightly higher than regular cements, increasing the chance of pretesting failure because of inadequate distribution of stress. An important issue is the variation in the total number of specimens. It occurs due to small differences in width dimension that occurs during the sectioning process, i.e., positioning of the saw, or due to errors in beam-shaped handling.

Despite the limitations of this in vitro study, such as the small number of specimens, absence of pulpal pressure simulation, and only three different luting approaches, the $\mu$ TBS values obtained

\section{References}

1. Aggarwal V, Logani A, Jain V, Shah N. Effect of cyclic loading on marginal adaptation and bond strength in direct vs. indirect class II MO composite restorations. Oper Dent. 2008 Sep-Oct;33(5):587-92.

2. Scherrer SS, Cesar PF, Swain MV. Direct comparison of the bond strength results of the different test methods: a critical literature review. Dent Mater. 2010 Feb;26(2):e78-93.

3. De Munck J, Van Landuyt K, Peumans M, Poitevin A, Lambrechts $\mathrm{P}$, Braem $\mathrm{M}$, et al. A critical review of the durability of adhesion to tooth tissue: methods and results. J Dent Res. 2005 Feb;84(2):118-32.

4. Van Meerbeek B, De Munck J, Yoshida Y, Inoue S, Vargas $\mathrm{M}$, Vijay $\mathrm{P}$, et al. Buonocore memorial lecture. Adhesion to enamel and dentin: current status and future challenges. Oper Dent. 2003 May-Jun;28(3):215-35.

5. Kanca J 3rd. Improving bond strength through acid etching of dentin and bonding to wet dentin surfaces. J Am Dent Assoc. 1992 Sep;123(9):35-43.

6. Tay FR, Pashley DH, Suh BI, Carvalho RM, Itthagarun A. Single-step adhesives are permeable membranes. J Dent. 2002 Sep-Nov;30(7-8):371-82.

7. Chiba Y, Rikuta A, Yasuda G, Yamamoto A, Takamizawa $\mathrm{T}$, Kurokawa $\mathrm{H}$, et al. Influence of moisture conditions on dentin bond strength of single-step self-etch adhesive systems. J Oral Sci. 2006 Sep;48(3):131-7.

8. Faria-e-Silva AL, Fabião MM, Sfalcin RA, Meneses MS, Santos-Filho PC, Soares PV, et al. Bond strength of one-step directly correlated with the importance of correctly following the clinical procedures for resin cement application. Furthermore, once the small differences among materials are detected in normal situations, adverse situations must be tested to attempt to create a clinical situation.

\section{Conclusion}

On the basis of the present results, the conclusions are as follows: (1) Delayed cementation did not influence $\mu \mathrm{TBS}$ of indirect composite resin restorations after dentin hybridization; (2) Regular resin cement with three-step etch-and-rinse adhesive system showed the best performance; and (3) All groups had comparable $\mu \mathrm{TBS}$ values even under unfavorable conditions, such as suboptimal dentin moisture for self-adhesive resin cement, which is less sensitive to variations. adhesives under different substrate moisture conditions. Eur J Dent. 2009 Oct;3(4):290-6.

9. Zander-Grande C, Ferreira SQ, Costa TR, Loguercio AD, Reis A. Application of etch-and-rinse adhesives on dry and rewet dentin under rubbing action: a 24-month clinical evaluation. J Am Dent Assoc. 2011 Jul;142(7):828-35.

10. Stewardson D, Creanor S, Thornley P, Bigg T, Bromage C, Browne A, et al. The survival of Class $\mathrm{V}$ restorations in general dental practice: part 3, five-year survival. Br Dent J. E142012 May 11; 212(9):E14.doi:10.1038/sj.bdj.2012.367.

11. Sanares AM, Itthagarun A, King NM, Tay FR, Pashley DH. Adverse surface interactions between one-bottle light-cured adhesives and chemical-cured composites. Dent Mater. 2001 Nov;17(6):542-56.

12. Barcellos DC, Batista GR, Silva MA, Rangel PM, Torres CR, Fava M. Evaluation of bond strength of self-adhesive cements to dentin with or without application of adhesive systems. J Adhes Dent. 2011 Jun;13(3):261-5.

13. Viotti RG, Kasaz A, Pena CE, Alexandre RS, Arrais CA, Reis AF. Microtensile bond strength of new self-adhesive luting agents and conventional multistep systems. J Prosthet Dent. 2009 Nov;102(5):306-12.

14. Rocha C, Faria-e-Silva A, Peixoto A. Bond strength of adhesive luting agents to caries-affected dentin. Oper Dent. 2014 Jul-Aug;39(4):383-8.

15. Holderegger C, Sailer I, Schuhmacher C, Schläpfer R, Hämmerle C, Fischer J. Shear bond strength of resin cements to human dentin. Dent Mater. 2008 Jul;24(7):944-50. 
16. Hiraishi N, Yiu CK, King NM, Tay FR. Effect of pulpal pressure on the microtensile bond strength of luting resin cements to human dentin. Dent Mater. 2009 Jan;25(1):58-66.

17. De Munck J, Vargas M, Van Landuyt K, Hikita K, Lambrechts P, Van Meerbeek B. Bonding of an auto-adhesive luting material to enamel and dentin. Dent Mater. 2004 Dec;20(10):963-71.

18. Escribano N, de la Macorra JC. Microtensile bond strength of self-adhesive luting cements to ceramic. J Adhes Dent. 2006 Oct;8(5):337-41.

19. Sarkis-Onofre R, SkupienJA, Cenci MS, Moraes RR, Pereira-Cenci $T$. The role of resin cement on bond strength of glass-fiber posts luted into root canals: a systematic review and meta-analysis of in vitro studies. Oper Dent. 2014 Jan;39(1):E31-44.

20. Moosavi H, Hariri I, Sadr A, Thitthaweerat S, Tagami J. Effects of curing mode and moisture on nanoindentation mechanical properties and bonding of a self-adhesive resin cement to pulp chamber floor. Dent Mater. 2013 Jun;29(6):708-17.

21. Soares CG, Carracho HG, Braun AP, Borges GA, Hirakata LM, Spohr AM. Evaluation of bond strength and internal adaptation between the dental cavity and adhesives applied in one and two layers. Oper Dent. 2010 Jan-Feb;35(1):69-76.

22. Perdigão J, Sezinando A, Monteiro PC. Effect of substrate age and adhesive composition on dentin bonding. Oper Dent. 2013 May-Jun;38(3):267-74.

23. Pashley DH,Sano H, Ciucchi B, Yoshiyama M, Carvalho RM. Adhesion testing of dentin bonding agents: a review. Dent Mater. 1995 Mar;11(2):117-25.

24. Pashley DH, Carvalho RM, Sano H, Nakajima M, Yoshiyama M, Shono Y, et al. The microtensile bond test: a review. J Adhes Dent. 1999 Winter;1(4):299-309. 